\title{
TENDÊNCIAS DA EDUCAÇÃO A DISTÂNCIA EM INSTITUIÇÕES DE ENSINO SUPERIOR NO BRASIL DO SÉCULO XXI
}

Trends of distance education in institutions of higher education in Brazil of the XXI century

\author{
OLIVEIRA, Ana Cristina Barbosa de. Discente do curso de Especialização Lato Sensu em \\ Educação, Contemporaneidade e Novas Tecnologias \\ Universidade Federal do Vale do São Francisco. E-mail: chrisbarbosa_2@hotmail.com
}

\author{
SOUZA, Aline Monia Alves de Carvalho. Discente do curso de Especialização Lato Sensu \\ em Educação, Contemporaneidade e Novas Tecnologias \\ Universidade Federal do Vale do São Francisco. E-mail: aline55mone@gmail.com
}

\author{
SOARES, Andréa de Souza Silva. Discente do curso de Especialização Lato Sensu em \\ Educação, Contemporaneidade e Novas Tecnologias \\ Universidade Federal do Recôncavo da Bahia E-mail: deacefet@yahoo.com.br
}

\begin{abstract}
FLORÊNCIO, Roberto Remígio. Orientador TCC do curso de Especialização em Educação, Contemporaneidade e Novas Tecnologias - UNIVASF; Mestre em Educação, Cultura e Territórios Semiáridos - UNEB; Professor IF Sertão PE, campus Petrolina Zona Rural. Instituto Federal de Educação, Ciência e Tecnologia do Sertão Pernambucano. E-mail: betoremigio@yahoo.com.br
\end{abstract}

\section{RESUMO}

A Educação Superior no Brasil tem apresentado um significativo aumento na oferta de vagas e a Educação a Distância apresenta um percentual cada vez maior nessa política de desenvolvimento universitário, percebido no Brasil desde o início deste século. O presente manuscrito tem o objetivo de analisar a EaD no Brasil contemporâneo, reconhecendo a importância da participação das IES na democratização do Ensino Superior, mas observando criticamente o filão desse mercado enquanto elemento constituinte de promoção de competências e habilidades para o exercício profissional. A pesquisa ocorreu durante os meses de outubro/2017 a março/2018, em sites especializados e portais das principais instituições promotoras de cursos superiores nesta modalidade. Foi utilizada como metodologia da pesquisa, uma revisão bibliográfica e entrevistas com especialistas, utilizando os métodos de Análise de Conteúdo, de Bardin (2009). Os resultados são, além de um grande apanhado de informações sobre a problemática, fissuras paradigmáticas em relação ao ensino à distância, características da modalidade e uma análise sobre acesso, evasão e potencialidades dos cursos oferecidos de forma não presencial, além da apresentação sumária dos recursos e dispositivos das interfaces didáticas mais comuns nesta modalidade de ensino.

Palavras-chave: EaD; Inovações Tecnológicas; Interfaces Didáticas.

\begin{abstract}
Higher Education in Brazil has presented a significant increase in the supply of vacancies and Distance Education presents an increasing percentage in this policy of university development, perceived in Brazil since the beginning of this century. The purpose of this manuscript is to analyze the EaD in contemporary Brazil, recognizing the importance of the participation of $\mathrm{HEI}$ in the democratization of Higher Education, but critically observing the lode of this market as a constituent element of the promotion of skills and abilities for professional practice. The research took place during the months of October / 2017 to March / 2018, in specialized websites and portals of the main institutions promoting higher courses in this modality. A bibliographical review and interviews with specialists were used as methodology of the research, using the methods of Content Analysis, by Bardin (2009). The results are, besides a great collection of information about the problem, paradigmatic fissures in relation to distance education, characteristics of the modality and an analysis on access, avoidance and potentialities of the courses offered in a non-presential form, besides the brief presentation of the resources and devices of the most common didactic interfaces in this teaching modality.
\end{abstract}

Keywords: EAD; Technological Innovations; Didactic Interfaces. 
OLIVEIRA, A. C. B.; SOUZA, A. M. A. C.; SOARES, A. S. S.; FLORËNCIO, R. R.

Tendências da educação a distância em instituições de ensino superior no Brasil do século XXI

\section{Introdução}

A Educação a Distância (EaD) é a modalidade de ensino que mais cresce no Brasil, segundo dados do Ministério da Educação (MEC). Das mais de 3,8 milhões de matrículas do ensino superior, registradas entre os anos de 2003 a 2010, 33\% correspondia a cursos à distância, sendo a maioria na rede privada de ensino. Em 2014, segundo dados da Associação Brasileira de Educação a Distância (ABED), o total de matriculados já ultrapassava a marca de 3,3 milhões. Nos últimos três anos, o número de alunos em projetos credenciados de ensino a distância cresceu $213 \%$, enquanto nas instituições de ensino presencial, 54,8\%. Ainda, de acordo com o Censo da Educação Superior realizado em 2015 pelo Instituto Nacional de Estudos e Pesquisas Educacionais Anísio Teixeira (INEP), há no país 1.473 mil cursos superiores a distância ofertados, cujo crescimento é de $10 \%$ ao ano, desde 2010 . Atualmente, são mais de 1,3 milhão de estudantes matriculados, com crescimento de $50 \%$ entre os anos de 2010 e 2015.

Segundo o Professor Dr. Luciano Sathler, Diretor da Associação Brasileira de Educação a Distância (ABED) e Diretor de EAD da Universidade Metodista, os motivos para essa expansão são diversos, sendo os principais o Decreto $N^{\circ} 5622$, de 2005, que reconhece a EAD como uma modalidade de ensino, e sua consequente regulação pelo MEC, em 2006. "Ao mesmo tempo, nesses anos, nós tivemos o avanço da internet em todo o Brasil, com mais pessoas tendo acesso [...] e também uma demanda maior por ensino superior, que tem levado a uma busca de mais opções para conseguir o diploma”, explica Sathler (UNIVERSIA, 2016).

Para o professor, entre os benefícios oferecidos por essa modalidade estão as mensalidades mais acessíveis, os horários flexíveis e a possibilidade de estudar em qualquer lugar. 0 público adulto é muito grande, “já que a população brasileira está envelhecendo, e eles, geralmente, preferem a educação a distância, pois esta possibilita a flexibilidade de tempo e espaço, e também de ritmo de estudos", conta Sathler (UNIVERSIA, 2016).

A estratégia do MEC é ampliar a oferta de ensino superior no país para atingir a Meta 12 do Plano Nacional de Educação (PNE), que exige elevar a taxa bruta de matrícula na educação superior para 50\% e a taxa líquida em 33\% da população de 18 e 24 anos. (MEC.BR, 2017). Então, pensando nisso, gestores educacionais em parceria com o Ministério da Educação estão empenhados em promover mudanças no ensino superior EAD, e em especial o Governo Federal, em atingir suas metas (elevar o índice de pessoas com Ensino Superior, uma vez que esse percentual no Brasil ainda é muito baixo em relação aos países como Chile, Argentina e outros da América Latina), como informa o último censo do MEC (BRASIL, 2016).

Um fator importante na Educação à Distância, é a criatividade, porque é através dela que os recursos poderão ser utilizados na melhor forma possível, fazendo com que o aluno tenha $o$ aprendizado, buscando novas formas, com isso o celular e o computador são as plataformas favoritas na hora de acessar esse conteúdo. Segundo um estudo realizado pela Nielsen, 61\% dos brasileiros assistem vídeos pelo celular e $81 \%$ o fazem pelo computador (JOSÉ CALAZANS, 2016, p.14).

Em um país continental como o Brasil, repleto de desigualdades sociais, por questões políticoadministrativas e de territorialidade, a modalidade de EaD, através de uma plataforma democrática 
OLIVEIRA, A. C. B.; SOUZA, A. M. A. C.; SOARES, A. S. S.; FLORËNCIO, R. R.

Tendências da educação a distância em instituições de ensino superior no Brasil do século XXI

de ensino, traz a praticidade, economicidade e a inclusão. Segundo Belloni (2008), a modalidade de Ensino a Distância melhora a qualidade de ensino presencial e leva à população distante de instituições de ensino, conquistas na área educacional. Dessa forma, essa modalidade instrutiva oportuniza conhecimento, cultura e formação em diversas localidades brasileiras contribuindo para melhorar o nível de competência, instrução e habilidade das pessoas.

Considerando que vivemos em uma sociedade neoliberal e globalizada, a EaD seria a tendência já definida para atender às incitações político-econômicas e sociais, na sociedade das novas tecnologias da informação e comunicação (TIC), com parâmetros pedagógicos contemporâneos e inovadores tendo como produto, um perfil de aluno ainda não muito bem definido, mas totalmente diverso dos modelos tradicionais.

Diante deste cenário, surge a necessidade de realizar este estudo, com o objetivo de analisar as principais ferramentas tecnológicas de ensino-aprendizagem na prática educacional EaD contemporânea. Para isso, realizou-se um levantamento de dados, a partir de uma revisão de literatura, pesquisando os portais das instituições que promovem ensino não presencial e analisando, à luz da Análise de Conteúdo (BARDIN, 2010), seus sistemas de ensino, sua interação com as TIC e as possibilidades teórico-metodológicas que os expedientes e dispositivos demandam.

\section{História e contextualização da EaD no Brasil}

É possível compreender que a sociedade atual é fortemente marcada pelas informações produzidas por meio das visualidades presentes no contexto social, cultural e educacional. Somos "bombardeados" por noticiários, os mais diversificados existentes, comunicando-nos a respeito de política, religião, guerras, meio-ambiente, tragédias, entre outros. A velocidade frenética de tais informações chega fortemente impulsionada por inúmeros meios tecnológicos como a televisão, o computador, o tablet ou mesmo um aparelho celular. A respeito dos meios tecnológicos, pode-se acrescentar que afetam sobremaneira o campo educacional, trazendo-lhes mudanças significativas. A respeito disso, Kensky (2015, p. 133) salienta que "o ir à escola para se educar e aprender transforma-se em metáfora para a aprendizagem por diversas formas e meios, inclusive os digitais".

$\mathrm{Na}$ educação tradicional, o estudante é condicionado a estar no ambiente escolar todos os dias e uma porcentagem mínima de frequência é registrada a fim de que haja aprovação para a série seguinte. No entanto, nos dias atuais, uma das maneiras de instruir-se ou profissionalizar-se é por meio da EaD, modalidade esta que desestabiliza um conceito milenar de espaço físico para a aprendizagem: a escola. A EaD diz respeito a professores e alunos estarem ocupando espaços diferenciados, em toda ou na maior parte do tempo, no momento em que ocorre o aprendizado (MOTTA; GAVILON, 2010). Moran adiciona que esse contato entre o discente e o docente é mediado por tecnologias (2002).

Os primeiros registros da EaD no Brasil são datados a partir de 1904 e os cursos eram ofertados por correspondência, para datilógrafo (ALVES, 2011). Por volta de 1923, são ofertados cursos de Português, Francês, Silvicultura, Literatura Francesa, Esperanto, Radiotelegrafia e Telefonia. "Tinha início assim a Educação a Distância pelo rádio brasileiro” (ALVES, 2011, p. 88). 
OLIVEIRA, A. C. B.; SOUZA, A. M. A. C.; SOARES, A. S. S.; FLORËNCIO, R. R.

Tendências da educação a distância em instituições de ensino superior no Brasil do século XXI

Posteriormente, por volta de 1974, surge o Instituto Padre Reus e, na TV, “começam os cursos das antigas $5^{\mathrm{a}}$ à $8^{\mathrm{a}}$ séries (atuais $6^{\circ}$ ao $9^{\circ}$ ano do Ensino Fundamental), com material televisivo, impresso e monitores" (ALVES, 2011, p. 88). Lemgruber (s/d) adiciona que a partir dos anos 70, "a segunda geração da EaD ainda tendo como principal suporte o material impresso, passou a utilizar, cada vez mais, recursos como a televisão, fitas de áudio e vídeo, além da interação por telefone". $\mathrm{Na}$ época atual vivemos um momento onde a EaD é fundada "em redes de conferência por computador e estações de trabalho multimídia, destacando-se as possibilidades oferecidas pelo acesso à internet" (Lemgruber, $\mathrm{s} / \mathrm{d}$ ).

Em um simples deslocamento corpóreo, com a movimentação da mão a fim de ligar o aparelho tecnológico e em seguida, conectando-o à internet, o aluno se vê conectado ao curso pretendido, tendo a oportunidade de avançar por conteúdos, artigos e textos que thes despertem o interesse, sem haver a necessidade do deslocamento ao espaço físico da instituição ou biblioteca. Kensky (2015, p. 16) argumenta que a "facilidade de acesso à informação lhes garante condições para orientar suas próprias trilhas de aprendizagem, de acordo com seus interesses e necessidades" e acrescenta que "a participação em cursos online livres, com temas diversificados, thes possibilita uma formação em concordância com suas prioridades" (idem, ibidem).

A mediação pedagógica na EaD é constituída por uma equipe de profissionais capacitados, objetivando a instrução em relação às atividades propostas, visando sanar dúvidas e mediando o conhecimento. Sendo assim, esta envolve o professor, o tutor presencial e o tutor à distância. 0 professor é o responsável por conduzir o processo de ensino e aprendizagem, colocando o estudante em contato com o seu objeto de estudo, contribuindo para o seu aprendizado (MOTTA; GAVILON, 2010, p. 21). Dessa maneira, é ele o responsável teoricamente para ministrar da disciplina de sua responsabilidade, selecionando os materiais teóricos e definindo as atividades pedagógicas (MOTTA; GAVILON, 2010, p. 21).

O tutor presencial é a pessoa que integra o espaço físico, estando presente no polo de apoio com horários e dias definidos. Tem por objetivo auxiliar os alunos quanto ao material didático utilizado, às tecnologias de informação disponíveis e ao esclarecimento de dúvidas em relação aos conteúdos sob sua responsabilidade (MOTTA; GAVILON, 2010, p. 20). Ainda, para que a mediação ocorra de maneira satisfatória, existe o tutor a distância que mesmo distante espacialmente, tende a comunicar-se por meio do uso de recursos tecnológicos, proporcionando "a interação entre estudantes, incentivando-o à pesquisa e promovendo a construção coletiva de conhecimento" (MOTTA; GAVILON, 2010, p. 21).

As principais vantagens para essa modalidade de ensino consistem em economia de tempo em relação ao tráfego até a instituição, facilidade de acesso ao material, interação entre os alunos por meio do chat, além do atendimento à um público maior e diversificado (BARROSO, 2010, p. 54). Além de que, a tecnologia age como uma ferramenta de inclusão social, compartilhando saberes com mais pessoas e democratizando o conhecimento em todo o mundo (BARROSO, idem, ibidem).

É necessário acrescentar que nos dias atuais, mediante as demandas e necessidades da sociedade, é cobrado do profissional a sua qualificação profissional regularmente, onde, ambicionando por altos cargos e reconhecimento no mercado de trabalho, deve estar a par de cursos profissionalizantes e 
OLIVEIRA, A. C. B.; SOUZA, A. M. A. C.; SOARES, A. S. S.; FLORËNCIO, R. R.

Tendências da educação a distância em instituições de ensino superior no Brasil do século XXI

educação continuada. Para Barroso (2010, p. 44), "a educação passou a ter uma dinâmica diferenciada, determinada pela necessidade de novos conhecimentos e novas qualificações, denominada de educação continuada". Diante da assertiva, constata-se a função relevante que a EaD desempenha nessa sociedade informatizada, contribuindo para uma formação continuada e tornando o indivíduo a par dos conhecimentos disseminados na atualidade.

\section{Os caminhos da pesquisa}

A pesquisa constituiu-se de uma revisão de literatura, na qual optou-se por uma abordagem de natureza quantitativa e qualitativa, a partir de um levantamento de dados e de uma análise descritiva das principais ferramentas de Ensino Superior à Distância. Foi realizado levantamento bibliográfico, com foco no tema, sendo para isto, selecionados: tese de doutorado, dissertações, artigos em periódicos, livros, legislação pertinente e documentos oficiais do Ministério da Educação, consultados nas principais bases de dados de acesso à pesquisa Scielo, Google Acadêmico e ScienceDirect, entre outros. O material selecionado foi analisado separadamente com base na Análise de Conteúdo (AC) do método de Bardin (2009), que se preocupa com as seguintes questões: a organização da análise, a codificação de resultados, as categorizações, as inferências e, por fim, a informatização da análise das comunicações.

Para uma aplicabilidade coerente do método, de acordo com os pressupostos de uma interpretação das mensagens e dos enunciados, a Análise de Conteúdo deve ter como ponto de partida uma organização. As diferentes fases da AC organizam-se em torno de três etapas, conforme Bardin (2009): 1. A pré-análise; 2. A exploração do material; e 3. 0 tratamento dos resultados: a inferência e a interpretação (p.121). E, na seleção dos assuntos durante a pesquisa, adotou-se como critério de inclusão do material pesquisado as ideias centrais que representam o foco desta análise, visualizado nas concepções e representações do título, resumo e palavras-chave.

\section{Portais EaD e os dispositivos digitais de aprendizagem}

Com a expansão no acesso à internet e intranets, aumentaram as informações trocadas via web entre instituições, nos setores internos e externos, abarrotadas de documentos impressos, e-mail acumulados. Era necessário armazenar todas as informações em bancos de dados, pastas e subpastas diversas, tornando difícil a organização e localização de materiais importantes, ou seja, toda a documentação burocrática registrada e salva. O excesso de documentos armazenados nos computadores necessitava de solução, surgindo os portais para organizar todos os serviços prestados pelas instituições em um só ambiente via internet, de acordo com Turban e King (2004). O portal mantém o excesso de informações em um ambiente virtual de fácil acesso, utilizando sistemas de buscas e classificação avançados. Os portais são considerados pelos autores como "portas de entrada" da informação e classificados em Portais de publicação, Portais comerciais, Portais pessoais, Portais corporativos, Portais móveis. 
OLIVEIRA, A. C. B.; SOUZA, A. M. A. C.; SOARES, A. S. S.; FLORËNCIO, R. R. Tendências da educação a distância em instituições de ensino superior no Brasil do século XXI

As instituições normalmente têm uma equipe técnica de informática responsável pela criação e manutenção dos portais, ou podem contratar os serviços de uma Agência de Marketing Digital. Segundo a Agência de Marketing Digital: Geração Interativa (2016, p.11),

um portal é um site que se sobressai perante os sites comuns. Por isso, quem tem um portal geralmente tem mais credibilidade em seu ramo de atuação, pois este tipo de site transmite uma impressão de alta capacidade, liderança, supremacia e vanguarda.

As Instituições de Ensino Superior (IES) à distância no Brasil fazem uso de portais, apresentando homepages repletas de tecnologias informativas, que oferecem páginas de acesso a serviços. Geralmente esse ambiente virtual é composto por ícones com acesso a e-mail, biblioteca, portal do aluno, downloads, plataforma de ensino, conteúdo da história institucional, acesso a outros sites, entre diversos serviços. A página do portal deve disponibilizar com clareza as informações, facilitando as atividades a serem realizadas pelos usuários.

Portais Educacionais se diferenciam muito dos portais comerciais, na sua roupagem, devido à finalidade, ambos abusam de merchandising, porém, o portal de uma instituição de ensino a distância, tem que possibilitar o melhor acesso à informação e clareza na comunicação. Apesar disso, é fácil encontrar portais educacionais mistos, com características comerciais, pois as instituições privadas utilizam bastante da publicidade para atrair os estudantes.

São inúmeras as IES que ofertam cursos na Modalidade à distância no Brasil atualmente. No portal do MEC, é possível encontrar todas as instituições de EaD credenciadas, ou seja, autorizadas e reconhecidas para desenvolverem suas atividades no Ensino Superior. Num levantamento de instituições públicas e privadas que atuam nas 27 unidades federativas, credenciadas para cursos de graduação, encontraram-se:

Tabela 1 - Pesquisado em 29/01/2018, informações sujeitas a mudanças, devido área em evolução.

\begin{tabular}{|l|l|l|l|}
\hline ESTADO & NÚMERO DE INSTITUIÇÕES & ESTADO & NÚMERO DE INSTITUIÇÕES \\
\hline Acre (AC) & 475 & Paraíba (PB) & 610 \\
\hline Alagoas (AL) & 645 & Paraná (PR) & 1.210 \\
\hline Amapá (AP) & 370 & Pernambuco (PE) & 773 \\
\hline Amazonas (AM) & 608 & Piauí (PI) & 583 \\
\hline Bahia (BA) & 1.125 & Rio de Janeiro (RJ) & 982 \\
\hline Ceará (CE) & 912 & Rio G. do Norte (RN) & 600 \\
\hline Distrito Federal (DF) & 857 & Rio G. do Sul (RS) & 1.075 \\
\hline Espírito Santo (ES) & 853 & Rondônia (RO) & 616 \\
\hline Goiás (GO) & 884 & Roraima (RR) & 481 \\
\hline Maranhão (MA) & 746 & Santa Catarina (SC) & 985 \\
\hline Mato Grosso (MT) & 887 & São Paulo (SP) & 1.667 \\
\hline Mato G. do Sul (MS) & 823 & Sergipe (SE) & 523 \\
\hline Minas Gerais (MG) & 1.323 & Tocantins (TO) & 557 \\
\hline Pará (PA) & 846 & & \\
\hline
\end{tabular}

Fonte: Portal do MEC. Pesquisado em 29/01/2018, informações sujeitas a mudanças, devido área em evolução.

É observável que os estados pertencentes à Região Norte possuem uma quantidade inferior de instituições superiores $\mathrm{EaD}$ em relação às demais regiões, mesmo sendo a que apresenta maior necessidade, devido a grandes distâncias territoriais e difíceis condições de transportes. Segundo o Censo (2016) realizado pela ABED, a maioria das IES que ofertam EaD está na Região Sudeste com 37\%, seguida da Região Sul, com $27 \%$. O Centro-Oeste detém $11 \%$ do total e a Região Norte, $7 \%$. Números 
OLIVEIRA, A. C. B.; SOUZA, A. M. A. C.; SOARES, A. S. S.; FLORËNCIO, R. R.

Tendências da educação a distância em instituições de ensino superior no Brasil do século XXI

condizentes com a porcentagem populacional, em acordo com o nível de escolaridade das regiões brasileiras, sendo que as Regiões Sul e Sudeste juntas detêm 64\% de instituições EaD do país.

A Região Nordeste, com 18\% do total de IES que oferecem cursos EaD, será analisada mais detalhadamente a partir da Região Integrada de Desenvolvimento Econômico (RIDE) polo de PetrolinaPE e Juazeiro-BA. A partir do levantamento realizado no Portal do MEC, listamos apenas as IES credenciadas para os cursos de graduação na área de Administração e Administração Pública, em situação ativa, na modalidade EaD, no estado da Bahia, existem 46 cursos credenciados e em Pernambuco, são 38 IES credenciadas.

Na cidade de Juazeiro-BA são:

- UNIVERSIDADE PAULISTA - UNIP

- CENTRO UNIVERSITÁRIO CAMPOS DE ANDRADE - UNIANDRADE

- CENTRO UNIVERSITÁRIO dE MARINGá - UNICESUMAR - UNICESUMAR

- CENTRO UNIVERSITÁRIO INTERNACIONAL - UNINTER

- faculdade SUPERIOR DE ENSINO PROGRAMUS - ISEPRO

- UNIVERSIDADE ANHANGUERA - UNIDERP

- UNIVERSIDADE DO ESTADO DA BAHIA - UNEB

- UNIVERSIDADE NORTE DO PARANÁ - UNOPAR

- UNIVERSIDADE SALVADOR - UNIFACS

- UNIVERSIDADE FEDERAL DO VALE DO SÃo FRANCISCO- UNIVASF

E na cidade de Petrolina-PE são:

- CENTRO UNIVERSITÁRIO CAMPOS DE ANDRADE - UNIANDRADE

- CENTRO UNIVERSITÁRIO CLARETIANO - CEUCLAR

- CENTRO UNIVERSITÁRIO dE MARINGÁ - UNICESUMAR

- CENTRO UNIVERSITÁRIO DE ANÁPOLIS - UNIEVANGÉLICA

- CENTRO UNIVERSITÁRIO dE RIO PRETO - UNIRP

- CENTRO UNIVERSITÁRIO MAURÍCIO de NASSAU de MACEIÓ - UNINASSAU

- CENTRO UNIVERSITÁRIO INTERNACIONAL - UNINTER

- faCULDADE AIEC - AIEC / FAAB

- FACULDADE SUPERIOR DE ENSINO PROGRAMUS - ISEPRO

- UNIVERSIDADE ANHANGUERA - UNIDERP

- UNIVERSIDADE DO SUL DE SANTA CATARINA - UNISUL

- UNIVERSIDADE PAULISTA - UNIP

- UNITNIVERSIDADE NORTE DO PARANÁ - UNOPAR

- UNIVERSIDADE TIRADENTES - UNIT

- UNIVERSIDADE FEDERAL RURAL DE PERNAMBUCO - UFRPE

- UNIVERSIDADE FEDERAL DO VALE DO SÃO FRANCISCO - UNIVASF

As cidades de Juazeiro e Petrolina são vizinhas e possuem 8 instituições em comum na oferta do curso de Administração, confirmando as propostas da EaD que é atingir o máximo possível de estudantes no país. Como se pode observar, as instituições privadas que atuam nas cidades são maioria, 8 e 14 instituições privadas em cada respectiva cidade. De acordo com o censo EaD Brasil (2016) da ABED, as instituições privadas são predominantes na oferta de cursos $E a D$, representando cerca de $65 \%$. Este mesmo censo "contabilizou 561.667 alunos em cursos regulamentados totalmente 
OLIVEIRA, A. C. B.; SOUZA, A. M. A. C.; SOARES, A. S. S.; FLORËNCIO, R. R.

Tendências da educação a distância em instituições de ensino superior no Brasil do século XXI

à distância", destacando que o INEP no censo de 2015 constatou que 9\% das matrículas totais na EaD pertenciam às instituições públicas e que $91 \%$ correspondiam às instituições privadas.

Em um estudo produzido pela ABED (2016), o curso de Pedagogia lidera o ranking de matrículas EaD, com cerca de $25 \%$ do total nacional, em segundo lugar aparece o curso de Administração com 13,7\%, seguido por Serviço Social (7,4\%), Ciências Contábeis (7,2\%), Gestão de Recursos Humanos (6,9\%), Educação Física $(3,5 \%$,$) , Letras (2,8 \%)$ e Gestão Pública $(2,4 \%)$, que, juntos, correspondem a $75 \%$ dos cursos mais procurados em EaD.

Fazendo um comparativo entre os portais das instituições públicas e das instituições privadas, percebemos pontos em comum e outros que os diferenciam sobremaneira. Entre os itens comuns, na página inicial da maioria dos portais, a cor azul é predominante; o calendário universitário e o ementário de cursos são ícones constantes. Outros itens presentes são: exclusão de disciplinas, história sobre a $\mathrm{EaD}$, polos, acesso rápido, plataforma, atendimento acadêmico, sistema acadêmico (Siga), repositório de TCC, canal de Atendimento, cursos online, editais, sistema de processo seletivo, solicitações, notícias, contato, guia telefônico, perguntas frequentes e a parte de acessibilidade determinada a todos os sites governamentais pela a Portaria $\mathrm{N}^{\circ}$ 3, de 07 de maio de 2007 como (Ir para o conteúdo 1, Ir para o menu 2, Ir para a Busca 3, Ir para o rodapé 4, Mapa do Site).

De acordo com Licheski e Fadel (2013), os portais públicos federais devem apresentar-se uniformes nos seus conteúdos e nas páginas virtuais como intuito de possibilitar facilidade e acesso à informação a todos que usufruírem. Bem como facilitar a portabilidade e a democratização do processo. Já as instituições privadas possuem alguns desses links, mais investem mais na apresentação mercadológica, com cores chamativas, marketing de custos e benefícios, ofertas de vantagens, índice de qualidades dos cursos e quantidade de sua abrangência.

\section{Resultados e análises}

Com a expansão do Ensino Superior ofertado por universidades à distância, fez-se necessário o aprimoramento e aperfeiçoamento de ferramentas que viabilizassem a conexão entre o conhecimento transmitido e o alunado. Dessa feita, a conexão entre esses, ocorre por meio do Ambiente Virtual de Aprendizagem (AVA), que consiste em um "espaço fecundo de significação onde seres humanos e objetos técnicos interagem potencializando assim, a construção de conhecimentos" (SANTOS, 2003, p. 2).

Entende-se então, que o AVA consiste em uma sala de aula virtual onde o aluno tem participação ativa, por meio da transmissão do conhecimento, seja por meio de uma vídeo-aula, a participação em fóruns de discussão e atividades propostas, além de inúmeras outras tarefas. Tudo ocorrendo em espaços temporais diferenciados, mas com o mesmo objetivo: gerar o aprendizado.

Existem várias plataformas disponíveis com a finalidade de promover a concepção de ambientes de aprendizagem. Assim, nesse estudo, optou-se pela seleção de 3 das mais significativas delas. O critério avaliativo deveu-se ao fato de serem utilizadas em IES particulares de notório conhecimento para a região de Juazeiro - BA e Petrolina - PE, onde a propagação midiática das 
OLIVEIRA, A. C. B.; SOUZA, A. M. A. C.; SOARES, A. S. S.; FLORËNCIO, R. R.

Tendências da educação a distância em instituições de ensino superior no Brasil do século XXI

instituições está entre o topo das mais visualizadas. Foram encontradas as seguintes plataformas: Colaborar, Univirtus e Studeo.

A análise das instituições que utilizam as plataformas citadas ficou assim distribuída:

- Universidade Norte do Paraná (UNOPAR) - Plataforma Colaborar;

- Universidade UNINTER - Univirtus e

- Universidade Unicesumar - Studeo.

Eis um recorte delimitado das Plataformas, verificando seus principais recursos metodológicos:

Colaborar: Cronograma de curso, agenda de curso, web aulas, fórum de dúvidas, Sala do tutor, área acadêmica (com conteúdos do curso, biblioteca digital). É válido salientar que, os cursos são semipresenciais, onde os alunos devem ir à Universidade uma vez por semana e nos outros dias, o ensino é mediado por aparelho tecnológico.

Univirtus - Avisos, calendário, histórico escolar, roteiro de estudo, material complementar, avaliações, tutoria, fórum, trabalhos, chat, rádio web, informações, avisos.

Studeo - Informações e materiais da jornada acadêmica, vídeo-aulas disponíveis, mensagens, fóruns de discussão, atividades em diversos formatos, Material de Avaliação Prática de Aprendizagem (MAPA), material didático (impresso e online).

Para que o aluno tenha acesso à Plataforma e consiga acessar o AVA the é concedido um usuário e uma senha pessoal, podendo ser acessado de qualquer aparelho conectado à internet.

\section{Considerações Finais}

Este estudo permitiu uma análise de como a EaD das IES tem evoluído no Brasil e a importância dos recursos tecnológicos utilizados nos ambientes virtuais que impulsionam uma interação e cooperação entre todos os envolvidos no processo de ensino-aprendizagem. As interfaces proporcionam um estreitamento nas relações interpessoais professor e aluno, no desenvolvimento das atividades, questionamentos, feedbacks e avaliações, somente possíveis através de planejamentos didático-pedagógicos elaborados com o auxílio de metodologias e práticas educativas específicas, destinadas àquele público alvo.

Os portais educacionais representam um local repleto de ícones com serviços oferecidos pela instituição, servindo como fonte esclarecedora na oferta de cursos, emendas, mensalidades, editais, inscrições. Geralmente, são sites sofisticados que ajudam o usuário a encontrar a informação.

Mas, a adoção dos cursos superiores EaD em utilizar ambientes virtuais de aprendizagem está na equiparação do espaço de sala de aula físico e virtual, ambos são ambientes ricos em interfaces atrativas que podem proporcionar uma interação com o propósito da aprendizagem. 0 segundo (virtual) ainda é capaz de vencer as lacunas do espaço físico e do tempo, proporcionando comodidade e otimização do tempo.

No ensino à distância, o computador é a ferramenta principal para o aluno, através da internet, acessar o ambiente virtual, sua sala de aula, além de ser um elemento essencial de interação entre aluno e professor. Essa modalidade, cada vez mais presente na educação brasileira, vem alcançando grande número de pessoas, de diferentes classes sociais, regiões geográficas e faixas 
OLIVEIRA, A. C. B.; SOUZA, A. M. A. C.; SOARES, A. S. S.; FLORËNCIO, R. R.

Tendências da educação a distância em instituições de ensino superior no Brasil do século XXI

etárias, interessadas em realizar o sonho de cursar o ensino superior, aperfeiçoar os estudos ou incrementar o currículo.

Duas características dessa revolução tecnológica na educação brasileira despertam o interesse das pesquisas socioculturais: as mudanças no ensino, através de novas metodologias e quebra de (pré)conceitos sobre a autonomia dos estudantes; e as transformações sociais que a EaD pode proporcionar, como uma maior inclusão ao Ensino Superior, tanto pelo poder de abrangência territorial, como pela comodidade de receber/executar a formação sem deslocamento, muitas vezes impossível para pessoas com limitações físicas e/ou econômicas de locomoção. Ambas fissuras paradigmáticas podem proporcionar uma mudança no quadro geral do nível de formação do povo brasileiro.

\section{Referências}

ABEP - Associação Brasileira de Empresas de Pesquisa. Censo EAD Brasil ,2016 Disponível em:< http://abed.org.br/censoead2016/Censo_EAD_2016_portugues.pdf>. Acesso em: 4 de Dez. 2017.

ABMES. Portaria normativa $N^{\circ}$ 11, de 20 de junho de 2017, Associação Brasileira de Mantenedoras de Ensino Superior. Disponível em:< https://abmes.org.br/arquivos/legislacoes/Port-Normativa-0112017-06-20.pdf>. Acesso em: 20 de jan 2018.

ALVES, Lucineia. Educação a distância: conceitos e história no Brasil e no mundo. Disponível em: abed.org.br/revistacientifica/Revista_PDF_Doc/2011/Artigo_07.pdf> Acesso em: 31 de jan. 2018.

ARETIO, L. G. La educación a distancia: De la teoria a la práctica. Barcelona: Editorial Ariel, 2001.

AVA - Ambiente Virtual de Aprendizagem - UNIVIRTUS - UNINTER. Disponível em: <https://www.youtube.com/watch?v=j7HFHMM_FEg> Acesso em 26 de fev. 2018.

AZEVEDO, Wilson. Educação a distância na universidade do século XXI. 2000. Disponível em: <http://www.aquifolium.com.br/educacional/artigos/spof2.html>. Acesso em 19 fev 2018.

BARDIN, L. Análise de Conteúdo. Lisboa, Portugal; Edições 70, LDA, 2009.

BARROSO, Marcella. 0 ensino de artes na educação a distância: reflexões, benefícios e limites. Disponível em: uninter.com/intersaberes/index.php/revista/article/viewFile/161/128. Acesso em $01 \mathrm{de}$ fev. 2018.

BELLONI, Maria Luiza. Educação a Distância. Campinas: Autores Associados, 2008.

BRASIL. Leis e Diretrizes e Bases da Educação Nacional. Decreto n. 5.622, de 19 de dezembro de 2005. Regulamenta o art. 80 da Lei 9.394/96, 20 dez. 1996. Estabelece as diretrizes e bases da educação nacional. Diário Oficial da União, Brasília, ano 134, n. 248, p. 27833-27841, dez. 2005. Disponível em: <http:// portal.mec.gov.br/seed/arquivos/pdf/dec_5622.pdf>. Acesso em: 15 jan. 2018.

BRASIL. Lei $\mathrm{n}^{\circ} 13.620$, de 15 janeiros de 2018. Disponível em: http://www.planalto.gov.br/ccivil_03/_ato2015-2018/2018/lei/L13620.htm Acesso em: 23 de jan $\underline{2018 .}$ 
OLIVEIRA, A. C. B.; SOUZA, A. M. A. C.; SOARES, A. S. S.; FLORËNCIO, R. R.

Tendências da educação a distância em instituições de ensino superior no Brasil do século XXI

BRASIL. Lei $\mathrm{N}^{\circ} 13.005$, de 25 de junho de 2014. Disponível em: < http://www.planalto.gov.br/CCIVIL_03/_Ato2011-2014/2014/Lei/L13005.htm. > Acesso em: 23 de jan 2018.

BRASIL. Lei de Diretrizes e Bases da Educação, 20 de dezembro de 1996. Disponível em:< http:/ / www.planalto.gov.br/Ccivil_03/leis/L9394.htm>. Acesso em 15 de jan. 2018.

COLABORAR. <http://www.unoparead.com.br/unopar/nosso-sistema.jsp> Acesso em 23 de Nov. 2017. Disponível em: <https://querobolsa.com.br/revista/unopar-colaborar> Acesso em 26 de fev. 2018.

COMISSÃO EUROPEIA, (2002). Educação e formação na Europa: sistemas diferentes, objectivos comuns para 2010. Luxemburgo: Serviço das Publicações Oficiais das Comunidades Europeias

COUTINHO, C. P. (2006). Utilização de blogues na formação inicial de professores: um estudo exploratório. In PANIZO et al (Eds.) Proceedings of the 8th International Symposium on Computers in Education, (Vol 2), pp. 157-164.

COUTINHO, Clara Pereira, BOTTENTUIT JUNIOR, João Batista. Blog e Wiki: Os Futuros Professores e as $\begin{array}{llllll}\text { Ferramentas } & \text { da } & \text { 2007. Web } & \text { Disponível } & \text { em: }\end{array}$ <https://repositorium.sdum.uminho.pt/bitstream/1822/7358/1/Com\%20SIIE.pdf>. Acesso em 20 fev. 2018.

GERAÇÃO INTERATIVA: Agencia de Marketing Digital. Disponível em: < http://geracaointerativa.com.br/noticias-marketing-digital/como-criar-um-portal.html>. Acesso em: 18 Jan. 2018.

GOMES, M. J. (2005). Blogs: um recurso e uma estratégia pedagógica . VII Simpósio Internacional de Informática Educativa - SIIE05 , p. 311-315. Disponível em: https://repositorium.sdum.uminho.pt/bitstream/1822/4499/1/Blogs-final.pdf. Acesso em $21 \mathrm{fev}$ 2018.

INEP- Instituto Nacional de Estudos e Pesquisas Educacionais Anísio Teixeira Legislação e Documentos. Censo da Educação Superior de 2016. Disponível em: <

file:///C:/Users/USER/Documents/p\%C3\%B3s\%20gradua\%C3\%A7\%C3\%A30\%201/TCC/apresentacao_ce nso_educacao_superior.pdf >. Acesso em: 4 Dez. 2017.

KENSKY, Vani Moreira. Educação e Internet no Brasil. Disponível em: <http://www.pucrs.br/ciencias/viali/doutorado/ptic/textos/Kenski.pdf> Acesso em 15 de jan. 2018.

LANDIM, C. M. das M. P. F. Educação a distância: algumas considerações. Rio de Janeiro: Edição do Autor, 1997.

LEMGRUBER, Márcio Silveira. Educação a Distância: para além dos caixas eletrônicos. Disponível em: <http://portal.mec.gov.br/arquivos/conferencia/documentos/marcio_lemgruber.pdf> Acesso em 31 de jan. 2018.

LICHESKI, L. C., \& FADEL, L. M. (2013). (In) acessibilidade digital. Revista Brasileira de Design da Informação, $\quad 10(2), \quad 104-122 . \quad$ Disponível $\quad$ em:< https://www.infodesign.org.br/infodesign/article/view/185. Acesso em 30 de Jan. 2018.

LITTO, FREDRIC M. As interfaces da EAD na educação brasileira. REVISTA USP, São Paulo, n. 100,p. 57 66, DEZEMBRO/JANEIRO/FEVEREIRO 2013-2014. Disponível em: <file:///C:/Users/USER/Downloads/76166-103941-1-SM.pdf>. Acesso em 21 fev 2018. 
OLIVEIRA, A. C. B.; SOUZA, A. M. A. C.; SOARES, A. S. S.; FLORËNCIO, R. R.

Tendências da educação a distância em instituições de ensino superior no Brasil do século XXI

LUCENA, M. (1997a). Um Modelo de Escola Aberta na Internet: O Projeto Kidlink no Brasil. Tese de Doutorado. Rio de Janeiro, RJ: COPPE/Sistemas/UFRJ.

LUCENA, M. (1997b). Um Modelo de Escola Aberta na Internet: Kidlink no Brasil. Rio de Janeiro, RJ: Editora Brasport. POSTMAN, N.,(1996). The End of Education (New York: Vintage Books).

MARTINS, Karine e FROM, Danieli Aparecida. A Importância da Educação a Distância na Sociedade Atual. Artigo. http://www.assessoritec.com.br/wp-content/uploads/sites/641/2016/12/ArtigoKarine.pdf. Acesso em 11 de fevereiro de 2018.

MICHAELIS. Disponível em: <http://michaelis.uol.com.br/moderno-portugues/busca/portuguesbrasileiro/delivery/> Acesso em 31 de jan. 2018.

MIRANDA, Luísa Augusta Vara. Educação Online: Interacção e Estilos de Aprendizagem de Alunos do Ensino Superior numa Plataforma Web. Tese de doutoramento em educação. Universidade do Minho Braga, 2005.2 Disponível em: <https://bibliotecadigital.ipb.pt/bitstream/10198/1120/1/TeseDoutoramento_LuisaMiranda.pdf >. Acesso em: 11 fev. 2018.

MORAN, José. $O$ que é educação a distância. Disponível em: <http://www2.eca.usp.br/moran/ wpcontent/uploads/2013/12/dist.pdf> Acesso em 31 de jan. 2018.

MOTTA, Alexandre; GAVILON, Igor; Introdução à educação a distância e ambiente virtual de ensino - aprendizagem. Florianópolis : Publicações do IF-SC , 2010. 92 p. : il. ; 27,9 cm.

PEREIRA, Alice Theresinha Cybis, SCHMITTE Valdenise, DIAS, Maria Regina Álvares C. Livro Ambientes Virtuais de Aprendizagem. 2007.2 Disponível em: <http://www.pucrs.br/ciencias/viali/tic_literatura/artigos/ava/2259532.pdf>. Acesso em $20 \mathrm{de}$ fev. 2018.

PILLA, Bianca Smith. Desenvolvimento de um Sistema de avaliação de e-learning corporativo. Programa de pós-Graduação em administração. UFRGS, Porto alegre. 2007. Disponível em: $<$ https://www.lume.ufrgs.br/bitstream/handle/10183/10673/000600039.pdf?sequence=1>. Acesso em 25 de fev 2018.

REVISTA DIÁLOGO EDUCACIONAL. A Educação a Distância no Brasil: conceitos e fundamentos. Marcio Mugnol. Curitiba, v. 9, n. 27, 2009.

SANTOS, Edméa Oliveira dos. Ambientes Virtuais de Aprendizagem: Por autorias livre, Pluraise Gratuitas. Disponível em: <http://www.comunidadesvirtuais.pro.br/hipertexto /home/ava.pdf> Acesso em 26 de fev. de 2018.

SANTOS, Júlio César F. Aprendizagem Significativa: modalidades de aprendizagem e o papel do professor. 2 ed. Porto Alegre, Rio Grande: Editora Mediação Distribuidora e Livraria Ltda., 2008.

TURBAN, E.; KING, D. Comércio Eletrônico: Estratégia e Gestão. São Paulo: Pearson, 2004.

UNINTER. Disponível em: <http://univirtus.uninter.com/ava/web/> Acesso em 23 de Nov. de 2017.

UNICESUMAR. Disponível em: <http://online.universo.edu.br/universo-ead/> Acesso em 25 de jan. de 2018.

UNICESUMAR EAD. Studeo (Ambiente Virtual de Aprendizagem). Disponível em: https://www.youtube.com/watch?v=XTUXPhVCLoQ Acesso em 25 de jan. de 2018. 